\title{
Acquisition and retention of avoidance behaviors following septal lesions or scopolamine injections in rats*:
}

\author{
ELIZABETH WORSHAM and LEONARD W. HAMILTON $\dagger$ \\ Rutgers University, New Brunswick, New Jersey 08903
}

\begin{abstract}
Scopolamine injections and septal lesions were found to have similar behavioral effects on both the acquisition and retention of a two-way avoidance task. However, on a jump-up task, these two manipulations did not have similar effects. Scopolamine impaired the acquisition of a jump-up avoidance such that the animals did not even learn the response, whereas septal lesions resulted in no change in acquisition of this task. Septal lesions prior to retention testing resulted in significantly shorter latencies to jump, but scopolamine injections were found to impair retention of this task. These results were interpreted to support the hypothesis that multiple functional systems may be represented within the septum.
\end{abstract}

An enhancement of shuttlebox avoidance responding following septal lesions in rats and cats is one of the most consistent findings in the literature (e.g., Fox, Kimble, \& Lickey, 1964; King, 1958; McCleary, 1961). However, septal lesions have been found to impair performance on most other avoidance tasks, including passive avoidance, one-way active avoidance, and forced extinction of an avoidance response (Lubar, 1964; McCleary, 1961; Zucker \& McCleary, 1964). These phenomena have been interpreted to mean that animals with septal lesions are deficient in the ability to suppress learned responses (McCleary, 1961, 1966).

Some results are not so easily explained by a deficiency in response suppression. Zucker (1965) has reported a facilitation of one-way active avoidance by septal lesions, and other studies have reported either no change or an impairment in the rate of acquisition of this task following septal lesions (Hamilton, 1969; Lubar, 1964; McNew \& Thompson, 1966; Kriekhaus et al, 1964; Zucker \& McCleary, 1964). Deagle and Lubar (1971), using a procedure without handling between trials, have reported no change in one-way avoidance in hooded rats with septal lesions, but an impairment in avoidance with albino rats with septal lesions. They suggest using caution in generalizing across strains of rats and different tasks.

Hamilton, Kelsey, and Grossman (1970) have suggested a functional differentiation between the lateral (inhibitory) and medial (facilitatory) septal nuclei in rats. They found that lesions restricted to the lateral septal nuclei resulted in an impairment in passive

*This research was supported by grants to L. W. Hamilton from the National Institute of Mental Health (No. MH 16448) and from the Rutgers Research Council and was completed during the tenure of an NDEA fellowship to E. Worsham. This report is based upon research conducted by the first author in partial fulfillment of the requirements for the degree of Master of Science at Rutgers University Department of Psychology. The technical assistance of P. Gottlieb is gratefully acknowledged.

$\dagger$ Requests for reprints should be sent to Leonard W. Hamilton, Department of Psychology, Rutgers University, New Brunswick, New Jersey 08903. avoidance, but that there was little effect on position-habit reversal. Lesions producing extensive damage to the septo-hippocampal system and the lateral septal nuclei did not affect passive avoidance, but did impair performance on a position-habit reversal task. Shuttlebox acquisition was enhanced by lesions in either the medial or lateral septal nuclei, and by unilateral septal lesions or large bilateral septal lesions involving both medial and lateral septal nuclei (Hamilton, 1970). Donovick (1968) found a facilitation of shuttlebox avoidance and no impairment of a reversal task following middle and posterior septal lesions which did not block hippocampal theta waves. Anteromedial lesions disrupted the reversal task, enhanced shuttlebox performance, and blocked hippocampal theta activity. Miczek et al (1972) have reported different postoperative time courses for the effects of septal lesions on shuttlebox avoidance, passive avoidance, and reactivity to footshock. These patterns of results suggest that multiple functional systems may be represented within the septal area.

Recent research has shown that some anticholingergic drugs (e.g., scopolamine hydrobromide and atropine sulfate) produce certain behavioral changes similar to the effects produced by septal lesions. Douglas and Isaacson (1966) have found that scopolamine abolishes theta activity in the hippocampus and reduces the synchronous firing of the septal cells which are the pacemakers for the hippocampal theta waves. Passive avoidance deficits (Meyers, 1965), impairment of spontaneous alternation (Douglas \& Isaacson, 1966: Squire, 1969), impairment of one-way active avoidance and facilitation of shuttlebox avoidance (Suits \& Isaacson, 1968) have all been reported following scopolamine injections in rats. Hearst (1959) has also shown that scopolamine injections increase the perseveration of inappropriate responses in a double discrimination problem.

The effects of scopolamine injections upon the retention of avoidance responses indicate that the compound disrupts response inhibition rather than 
recent memory. The retention of an active avoidance response is unaffected by scopolamine injections (Meyers et al, 1964), whereas the retention of a passive avoidance response is impaired (Meyers, 1965).

Carlton (1961) has suggested that scopolamine injections produce a blockade of a cholingergic inhibitory system which mediates the effects of nonreward. The experiments of Hamilton, McCleary, and Grossman (1968) demonstrated that microinjections of atropine into the septal area of cats produce behavioral deficits similar to those seen after septal lesions. They suggested that the drug may act, in part, on a cholingergic pathway which involves the septal area.

The results of Hamilton et al (1968) and Hamilton and Grossman (1969) are also consistent with the hypothesis that some of the behavioral functions of the septal area are mediated by cholinergic neurons. Hamilton and Grossman found an impairment of a shelf-jump avoidance following either microinjections of scopolamine into the septum or systemic injections of scopolamine, and facilitation of shuttlebox avoidance following systemic injections of scopolamine. Thus, as with septal lesions, the disruption of central cholinergic pathways with scopolamine may result in an impairment, facilitation, or no change in active avoidance responding depending on the testing situation.

\section{EXPERIMENT I TWO-WAY AVOIDANCE RESPONDING}

This experiment was done to extend the comparison between the effects of scopolamine injections and septal lesions in two-way avoidance performance. Both septal lesions and scopolamine have been found to facilitate two-way active avoidance acquisition (e.g., Suits \& Isaacson, 1968; Fox, Kimble, \& Lickey, 1964; Hamilton, 1969), but there is little information on the effects of either manipulation on retention of this avoidance task. Moore (1964) found an impairment of retention following septal lesions when the task had been learned preoperatively, but his results are hard to explain in light of any of the present theories of septal function. Scopolamine has been found to have no effect on the performance of a previously learned pole-jump avoidance response (Meyers et al, 1964). Herz (1968), however, has found a disruption of the same task which interacted with the degree of training (i.e., with overtrained animals, scopolamine had no effect on retention performance). In the present experiment, rats with septal lesions and rats receiving scopolamine injections were compared directly on both the acquisition and retention of a two-way avoidance response.

\section{Method}

Subjects

The Ss were 37 male albino rats obtained from Carworth Co. (CFE strain) and weighing approximately $150-200 \mathrm{~g}$ at the start of the experiment. They were housed singly under conditions of constant illumination with ad lib access to food and water.

\section{Apparatus}

The apparatus has been described in detail by Hamilton (1972), so only a brief description will be given here. A shuttlebox, made of clear Plexiglas, measuring $11.5 \times 51.0 \times$ $14.0 \mathrm{~cm}$ high, and with a guillotine door separating it into two identical compartments, was used. The grids could be electrified by a constant-current $(0.5-\mathrm{mA})$ shock source modified after Brown, Reus, and Webb (1961). The CS was a 6-W 120-V ac lamp mounted on either end of the apparatus.

\section{Procedures}

Testing. Prior to surgery, the rats were divided into five groups: the control group $(C-C, N=8)$, which was tested under both Phase 1 and Phase 2 as controls; the septal group (S-S, $\mathrm{N}=8$ ), which received septal lesions prior to Phase 1 ; the control-septal group $(C-S, N=8)$, which received septal lesions after Phase 1; the scopolamine group (Scop-Scop, $N=6$ ), which received intraperitoneal injections of scopolamine hydrobromide of $1.0 \mathrm{mg} / \mathrm{kg} 20 \mathrm{~min}$ prior to Phase 1 and Phase 2 testing; and the control-scopolamine group ( $\mathrm{C}-\mathrm{Scop}, \mathrm{N}=7$ ), which were controls during Phase 1 and received scopolamine injections only prior to Phase 2 testing.

Ten days following surgery, the Phase 1 testing was begun. The $S$ was brought into the experimental room and placed into the appropriate starting chamber for $30 \mathrm{sec}$ before the onset of the CS. The CS was light onset in the chamber in which the rat was located. The CS-UCS interval was $10 \mathrm{sec}$. All Ss were forced to escape on the first trial to insure that they all experienced the UCS. This was done by delaying the raising of the door until UCS onset. After the rat was completely within the "safe" chamber, the trial was terminated and the animal remained in the "safe" chamber for a 30 -sec intertrial interval. Training was continued for 60 trials.

Phase 2 testing was done 10 days later using exactly the same procedure except that the first trial was not a forced escape. The Ss in the C-S group were operated on the day after Phase 1 testing.

Surgical and histological. Surgery was performed under Equithesin anesthesia (Jensen Salsbery, $0.25 \mathrm{cc} / 100 \mathrm{~g}$ body weight) injected intraperitoneally. Septal lesions were produced by passing $1.5 \mathrm{~mA}$ of anodal current for two $15-\mathrm{sec}$ periods through a single stainless steel electrode angled $15 \mathrm{deg}$ from the vertical and lowered stereotactically to the following deGroot (1959) coordinates: $A=7.6, H=1.0$, and $L=0.5 \mathrm{~mm}$ across the midline. The operated controls received the same treatment, except that the electrode was not lowered into the brain.

Following behavioral testing, the brain-damaged rats were injected with an overdose of Equithesin and perfused intracardially with saline followed by Formol saline. The brains were removed from the skull and stored in Formol saline. For histological verification of the lesion, every fifth 60-micron frozen section was stained with cresyl violet and examined microscopically.

Statistical analyses. All data were analyzed by means of a two-factor (repeated measures) analysis of variance (Winer, 1962). When a significant main effect was obtained, individual comparisons (.05 alpha level) were carried out using the Fisher test for the least significant difference (LSD test; Federer, 1955) to yield critical values for comparing group means.

\section{Results}

\section{Phase 1}

There were no significant differences among the 
control animals in Groups C-C, C-S, and C-Scop on the number of avoidances during Phase $1(\mathrm{~F}=1.95$, $\mathrm{df}=$ $2 / 18$ ), so they were combined to form a single control group (Con). All three groups improved over trials $(\mathrm{F}=$ $8.94, \mathrm{df}=4 / 72, \mathrm{p}<.01)$.

Rats which were tested in Phase 1 following either septal lesions (Group S-S) or scopolamine injections (Group Scop-Scop) made significantly more avoidances than did controls $(F=15.13, \mathrm{df}=2 / 30, \mathrm{p}<.01)$, but did not differ from each other (see Fig. 1A).

Similar differences were reflected in the response latencies. The three control groups (C-C. C-Scop, C-S) were not significantly different in their mean latencies to respond $(F=2.43, \mathrm{df}=2 / 18)$, with all three groups responding more rapidly over trials $(F=10.60$, df $=$ $4.72, \mathrm{p}<.001$ ), so they were again combined to form a single control group. There was a significant difference in mean latency to respond between the combined controls, Groups S-S and Scop-Scop ( $F=7.22$, df $=$ $2 / 30, p<.01)$. As can be seen in Fig. 1B, Group S-S showed the shortest latencies to respond and the controls had the longest latencies. Both Groups S-S and Scop-Scop were significantly faster than controls to respond [Fisher's LSD, $t(.05)=4.47$ ], and Group S-S was also significantly faster than Group Scop-Scop.

\section{Phase 2}

During Phase 2, the animals that had scopolamine injections or septal lesions during both phases (Groups S-S and Scop-Scop) continued to show a greater number of avoidances than the C.C group $(F=4.55, \mathrm{df}=2 / 16$, $\mathrm{p}<.05)$. The Fisher LSD yielded a critical value of $\mathrm{t}(.05)=8.98$, and all three groups were significantly different from each other. Group S-S made the greatest number of avoidances and showed the greatest improvement over Phase 1 (see Fig. 1C). Groups C-C and Scop-Scop showed little improvement from Phase 1, with Group Scop-Scop continuing to make a greater number of avoidances than the controls.

All three of these groups were significantly different on mean latency to respond $(\mathrm{F}=8.44, \mathrm{df}=2 / 16$, $\mathrm{p}<.01)$. The Fisher LSD test yielded a critical value of $t(.05)=6.46$. Group S-S again had the shortest latencies (see Fig. 1D).

The Ss that had scopolamine injections or septal lesions only prior to Phase 2 (Groups C-Scop and C-S) showed similar effects to those of Groups S-S and Scop-Scop. Both C-S and C-Scop groups had a significantly greater number of avoidances than Group C-C $(F=4.27, \mathrm{df}=2 / 18, \mathrm{p}<.05)$, but were not significantly different from each other [critical value, LSD, $\mathrm{t}(.05)=7.66$ ]. There was a significant Trials by Groups interaction $(F=2.86, \mathrm{df}=8 / 72 . \mathrm{p}<.01)$ due to the rapid improvement of rats in Group C.S and the gradual improvement of rats in Group C-Scop (see Fig. 1C). All three groups again showed a significant improvement over trials $(F=27.80 . \mathrm{df}=4 / 72, \mathrm{p}<.01)$.

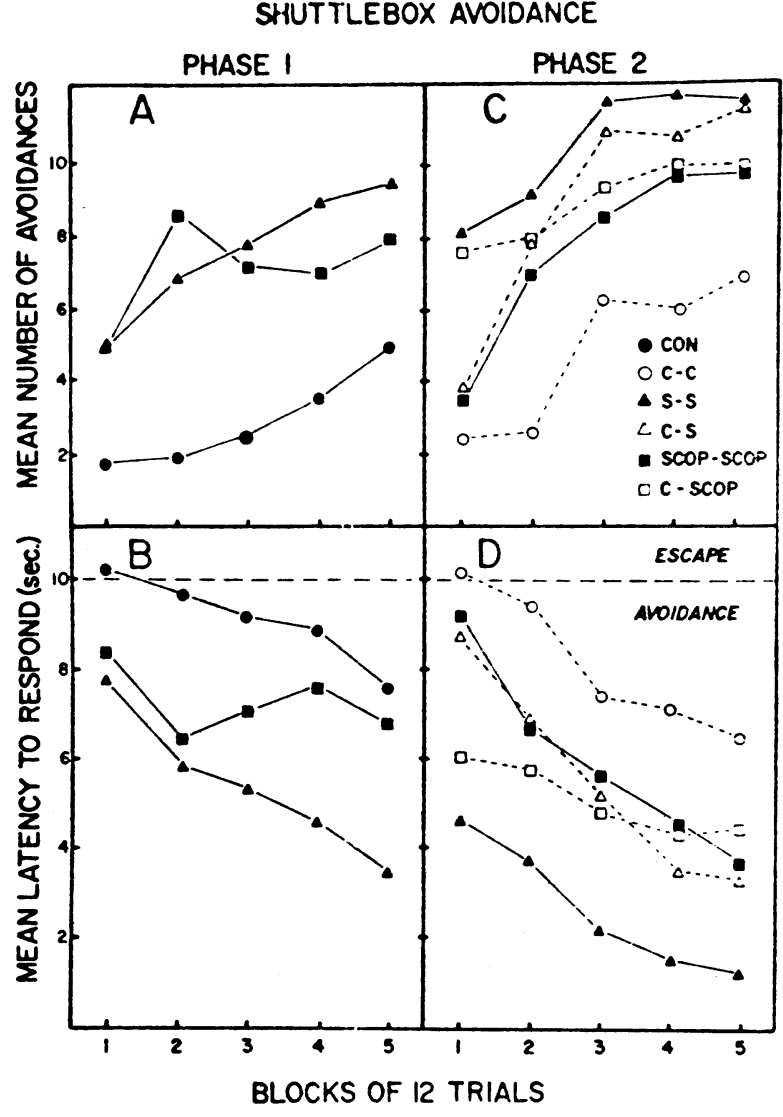

Fig. 1. Two-way avoidance responding plotted as a function of trials. Panels $A$ and $C$ represent the mean number of avoidances over trials. Panels $B$ and $D$ represent the mean latency to respond.

Groups C-S and C-Scop had significantly shorter latencies than Group C.C $(F=4.07 . \mathrm{df}=2 / 18, p<.05)$, but were not significantly different from each other [Fisher's LSD, $t(.05)=5.93)$. Again, there was a significant trials effect $(F=26.90 . \mathrm{df}=4 / 72, \mathrm{p}<.001)$ and a Trials by Groups interaction $(F=2.39, \mathrm{df}=8 / 72$, $\mathrm{p}<.05)$. This interaction can be seen in Fig. 1D: Both Groups C.C and C-S decreased their latency over trials. while Group C-Scop started at a lower latency and remained essentially stable over trials.

\section{Histological}

The lesions typically involved nearly total destruction of septal tissue bounded anteriorly by the genu of the corpus callosum, ventrally by the anterior commissure. posteriorly by the columns of the fornix, and dorsally by the corpus callosum. Occasionally. some unilateral sparing of the lateral septal nucleus was noted, but this was not observed to correlate with any behavioral differences. A typical lesion may be seen in Fig. 2. Histological examination revealed three of the lesions to be small and unilateral, so these animals were dropped 


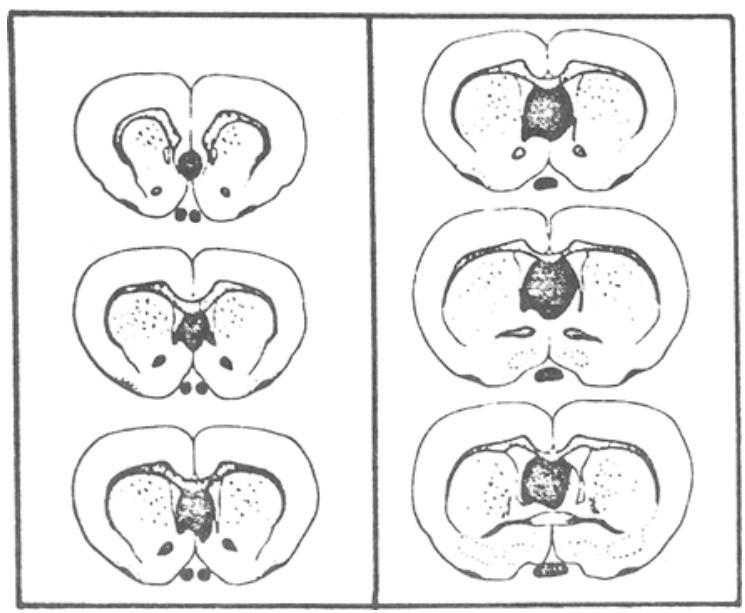

Fig. 2. Representative sections showing a typical septal lesion.

from statistical analyses. Two of the animals were from Group S-S and one was from Group C-S.

\section{EXPERIMENT II JUMP-UP AVOIDANCE RESPONDING}

Both septal lesions and scopolamine have been found to interfere with the acquisition of a shelf-jump avoidance (Hamilton, 1969; Hamilton \& Grossman, 1969). Rich and Thompson (1965) have reported an impairment of a preoperatively learned avoidance response following septal lesions. The rats had been trained to avoid shock by jumping onto a wall and hanging in response to a $5-\mathrm{sec}$ bright light CS. None of the animals showed any retention; however, rats with septal lesions freeze during intense light and this tendency may have been responsible for the deficit.

Meyers et al (1964) and Herz (1968) found that scopolamine interfered with acquisition but not with retention of a pole-jump response, unless the response was not well established. Since the results of Experiment I indicate that scopolamine injections and septal lesions have similar effects on both the acquisition and performance of a two-way shuttlebox task, the purpose of this experiment was to further test for parallel effects of scopolamine and septal lesions on a jump-up avoidance task.

\section{Method}

\section{Subjects}

The Ss were 41 male albino rats obtained from Carworth Co. (CFE strain). The average weight at the start of testing was $200 \mathrm{~g}$. The rats were individually housed and given ad lib access to food and water.

\section{Apparatus}

A Plexiglas box, measuring $30.5 \times 30.5 \times 39.4 \mathrm{~cm}$ high, was used as the testing chamber. A $30.5 \times 21.6 \mathrm{~cm}$ wire mesh screening was fastened flat to the back wall of the chamber $15.9 \mathrm{~cm}$ above the grid floor. The grid floor consisted of $0.5-\mathrm{cm}$ stainless steel rods placed $1.3 \mathrm{~cm}$ apart. A Mallory Sonalert audible signal (approximately $1,000 \mathrm{~Hz}$ ) was used as a CS. The CS was a continuous signal followed automatically $4.5 \mathrm{sec}$ after onset by the UCS. The UCS was an electric shock delivered through the grid floor by a constant-current Grason-Stadler shocker. with a limiting series resistance such that .25-mA of current passed through the rat. The apparatus was in a room measuring $2.44 \times 3.05 \mathrm{~m}$, with the only light source coming from a $15-\mathrm{W}$ bulb located above the apparatus.

\section{Procedures}

Testing. Prior to surgery, the Ss were divided into the same five groups as described in Experiment $I$ : $C-C(N=7)$, S-S $(N=7)$, C-S $(N=7)$, Scop-Scop $(N=12)$, and C-Scop $(N=8)$.

On the 10 th postoperative day, the $S$ was placed in the testing chamber for $10 \mathrm{~min}$ of exploration. Immediately after this $10 \mathrm{~min}$, the CS was presented for the first trial, followed $4.5 \mathrm{sec}$ later by the UCS. Termination of the CS and UCS occurred as soon as the rat made a jump-up response (jumping up and hanging onto the wire mesh), or at the end of $60 \mathrm{sec}$ if no jump-up response occurred. Thus, four types of responses were possible: (1) a failure to make a jump-up response, (2) an escape-a response made any time during the UCS, (3) an avoidance-a jump-up response during the 4.5-sec CS-UCS interval, or (4) an anticipatory response-a jump-up made during the 60-sec intertrial interval. An avoidance, escape, or anticipatory response prolonged the next trial by the amount of time spent holding onto the wire, plus a $60-\mathrm{sec}$ intertrial interval which began when the rat returned to the grid floor. In the case of no response, the $60-\mathrm{sec}$ intertrial interval began immediately upon termination of the CS and UCS. All Ss were tested for 60 trials, except for those which made five consecutive failures to jump up and were discarded.

Phase 2 testing was done 10 days later, following exactly the same procedure, except that only $3 \mathrm{~min}$ were allowed for exploration. In the case of the $\mathrm{C}-\mathrm{S}$ group, surgery was performed on the day following Phase 1 testing.

Surgery and histology. All procedures were identical to those described in Experiment I.

\section{Results}

\section{Phase 1}

The three control groups (C-C, C-S, and C-Scop) were not significantly different on the number of nonshock trials or mean latency to jump up ( $\mathrm{F}<1$ in both cases), so they were combined to form a single control group (Con). There was a significant increase in the number of nonshock trials over trials $(F=5.38, \mathrm{df}=4 / 56, \mathrm{p}<.01)$, but there was no change in latency over trials $(\mathrm{F}<1)$.

There was no difference between Group S-S and the combined controls on the number of nonshock trials $(F<1)$, although there was a significant trials effect $(F$ $=5.59$, df $=4 / 76, p<.01)$. Group Scop-Scop was omitted from this analysis since 10 out of 12 Ss failed to learn the jump-up response (see Fig. 3A). A Fisher exact probability test (Siegel, 1956), comparing controls and Group Scop-Scop on the number of learners vs nonlearners, resulted in a $p=.00098$. A comparison of Groups S-S and Scop-Scop yielded a $p=.028$. Thus, the 
rats in Group Scop-Scop were significantly inferior to both the control rats and the rats in Group S-S on the ability to learn the jump-up response.

There were no differences between the controls and Group S-S on latencies to jump $(\mathrm{F}<1)$, nor was there any change in latencies to jump over trials $(\mathrm{F}<1$; see Fig. 3B).

\section{Phase 2}

During Phase 2, Groups C-S, C-C, and C-Scop were significantly different on the number of nonshock trials $(\mathrm{F}=11.71, \mathrm{df}=2 / 14, \mathrm{p}<.01)$. A Fisher LSD test yielded a critical value of $t(.05)=6.68$. Groups $C$-S and C.C both improved over Phase 1 in the number of nonshock trials, but were no different from each other; however, Group C-Scop's performance was significantly impaired and they had even fewer avoidances during Phase 2 than they did during Phase 1 . There was a significant increase in the number of nonshock trials over trials $(\mathrm{F}=6.05, \mathrm{df}=4 / 56, \mathrm{p}<.01)$.

These three groups were significantly different on latencies to jump $(F=4.45, \mathrm{df}=2 / 14, \mathrm{p}<.05)$. A critical value of $t(.05)=31.71$ indicated that all three groups were different from each other. The performance of Group C-C remained stable over trials, whereas Group C-S had significantly shorter latencies, with almost all of their responses being anticipatory. The animals in Group C-Scop were much slower to respond than either of the other groups and also slower than they were during Phase 1 (see Fig. 3D).

There was no significant difference between Groups S-S and C-C on the number of nonshock trials or on latencies to jump ( $\mathrm{F}<1$ in both cases). There was a significant increase in the number of nonshock trials over trials $(F=4.61, \mathrm{df}=4 / 32, \mathrm{p}<.01)$, but there was no difference in latencies over trials $(F<1)$, indicating that although the groups were making more jump-up responses over trials, they were not doing it any faster.

\section{Histological}

The histological results were similar to those obtained in Experiment $I$ in terms of the extent of damage. Histological examination revealed that two of the lesions from Group S-S were small and unilateral, so they were dropped from the statistical analyses.

\section{DISCUSSION}

The rats which received septal lesions or systemic scopolamine injections during Phase 1 were superior to the controls on both the number of avoidance responses and on latency to respond in the two-way shuttlebox. It should be noted that neither septal lesions nor scopolamine injections produced any obvious behavioral changes that might account for this facilitation. The animals with lesions were not tested until 10 days

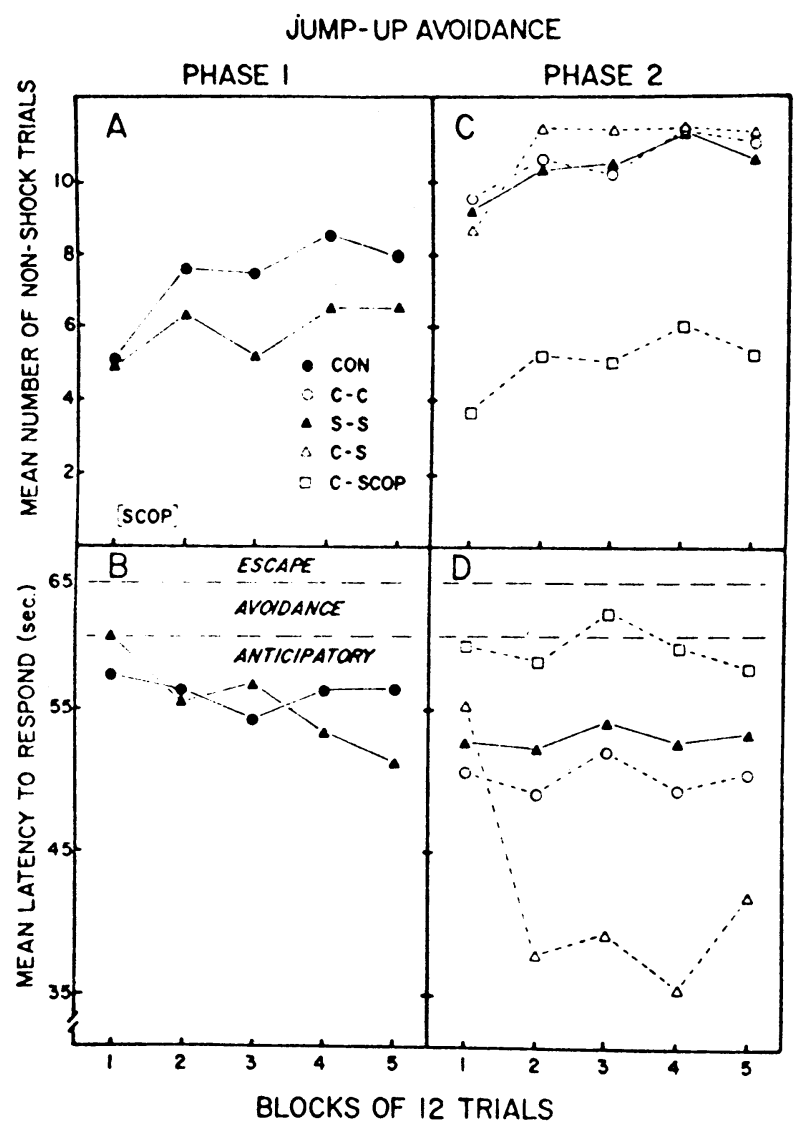

Fig. 3. Jump-up avoidance responding plotted as a function of trials. Panels $A$ and $C$ represent the mean number of nonshock trials over blocks of trials. Panels B and D represent the mean latency to respond.

postoperatively. By this time, they no longer displayed hyperemotionality. When the two-way avoidance was learned under normal conditions, septal lesions or scopolamine injections during Phase 2 produced a facilitation as they had in Phase 1. These data are not consistent with those of Moore (1964), who found an impairment with septal lesions when the shuttlebox task had been learned as a normal. These differing results may be attributable either to species differences or to procedural differences. Since disrupting central cholinergic pathways by scopolamine produced an effect similar to a septal lesion, these results support the hypothesis (Hamilton, 1969; Hamilton \& Grossman, 1969; Hamilton, McCleary, \& Grossman, 1968) that some of the behavioral functions of the septal area must be mediated by cholinergic neurons.

Neither the septal lesions nor the scopolamine injections produced a facilitatory effect on jump-up responding during Phase 1 . The animals with septal lesions performed the same as controls. Similar effects of septal lesions have been found on other avoiance tasks (Hamilton, 1969, 1972; Lubar, 1964; Zucker \& McCleary, 1964). Septal lesions have also been found to impair acquisition of a shelf-jump avoidance task 


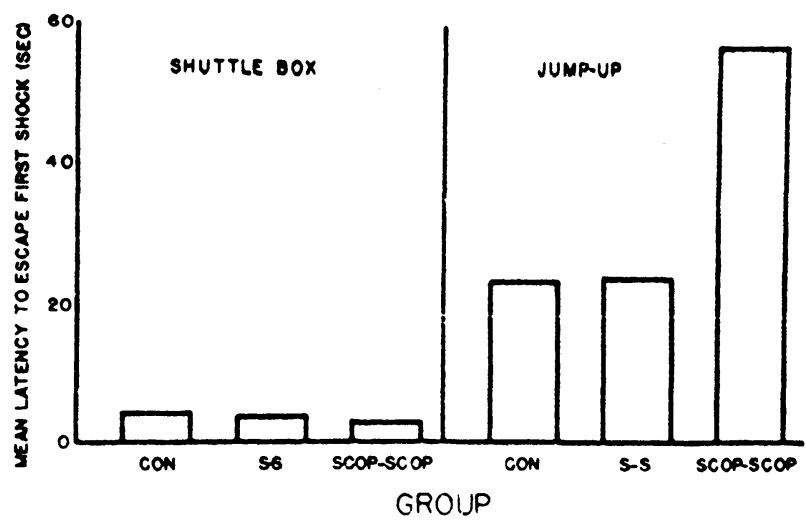

Fig. 4. The mean latency of the different groups to escape the first shock in Phase 1 of the two-way and jump-up avoidance tasks.

(Hamilton, 1969; McNew, 1966).

Scopolamine during Phase 1, however, produced a severe impairment-10 out of 12 animals did not learn the jump-up escape response. Similar impairments due to scopolamine have been found on one-way avoidance (Suits \& Isaacson, 1968), on a shelf-jump avoidance (Hamilton \& Grossman, 1969), and on a pole-jump avoidance (Meyers et al, 1964). In the Meyers et al study, few of the scopolamine Ss even learned the response, and only two Ss emitted any avoidances.

When the jump-up response was learned under normal conditions during Phase 1, septal lesions and scopolamine during Phase 2 produced opposite effects. A septal lesion in Phase 2 facilitated jump-up performance such that, although Group C-S and Group C-C animals had about the same number of nonshock trials, most of the responses made by Group C-S were anticipatory. The rats in Group C-Scop, however, were again impaired on jump-up performance-they had longer latencies to jump and fewer nonshock trials. Thus, on the jump-up task, scopolamine injections and septal lesions did not have the same effect on responding.

The differences in performance on the two tasks must be due to some fundamental differences in the two testing situations. The jump-up response, like the shelf-jump and pole-jump responses, requires the finding of a "safety zone" within the shock chamber itself. There were animals within several groups that did not learn the response (5 in Group Con, 1 in Group S-S, and 10 in Group Scop-Scop), and even the animals that did learn showed long initial latencies. The first responses to the shock in the jump-up apparatus (running into the walls, trying to escape beneath the grids, scratching at the walls, and exploring the corners) indicate that the animal is trying to escape the chamber. This is exactly what the animal must learn to do in the shuttlebox, and indeed, none of the animals in Experiment I failed to learn the response. In a recent Psychological Review article, Bolles (1970) has proposed that animals exhibit innate species-specific defense reactions (SSDRs) to aversive stimuli; these are flight, freeze, or fight. He further argues that whenever an animal is put into an aversive laboratory situation, all its behavior to a stimulus change is eliminated except these SSDRs. Thus, an avoidance response can be rapidly acquired only if it is an SSDR; other avoidance responses can be learned only by suppression of these SSDRs. Avoidance responses can be placed along a continuum of difficulty in which shuttlebox avoidance is easier than jump-up behavior since it requires one of these SSDRs. Bolles $(1969,1970)$ has found that rearing (which could be considered a part of learning the jump-up response) is not easily learned as a response even in an escape contingency. Bolles and Grossen (1969) have found that the most effective stimulus change for an avoidance response is not just any response which terminates a stimulus, but a response which results in a new location.

Using D'Amato's (1967) distinction between anticipatory responding and conditioned avoidance responding, anticipatory responses can be considered the "operant level" of what are commonly called avoidance responses. These occur independently of the avoidance contingency and provide the animal with an opportunity to learn the avoidance contingency. Since the escape response in the shuttlebox is high in the rat's response hierarchy (SSDR), none of the rats have difficulty acquiring the short latency escape response (see Fig. 4). However, normal rats are reluctant to perform the SSDR in anticipation of the shock onset because of the approach-avoidance conflict inherent in this task (e.g., McCleary, 1966; Olton \& Isaacson, 1968). Septal lesions and scopolamine injections appear to reduce the conflict of returning to a previously aversive location, thereby allowing the SSDR to occur more frequently as an avoidance response.

Since the jumping response is quite low in the response hierarchy, the animal must first learn to suppress the competing SSDRs. When short latency responses begin to occur, the escape response is well developed and avoidance responding requires a change in the pattern of responding. Hamilton (1969) suggested that septal lesions made the animal less flexible in changing its pattern of responding, such that they continue to make escape responses. In the present jump-up experiment, the rats with septal lesions performed about the same as controls; however, in Phase 2, the controls were making shorter latency responses. The same line of reasoning cannot be extended to Group Scop-Scop, since they did not even learn the response. It should be pointed out that when the jump-up response was learned under normal conditions, a septal lesion greatly decreased the latency to jump. One possible explanation is that once the animal has been exposed to the avoidance contingency, a septal lesion facilitates performance, as in the shuttlebox, by reducing any conflict inherent in hanging on to the wall.

Scopolamine injections did not have the same effect 
as septal lesions on jump-up behavior. Scopolamine impaired the performance of both the number of nonshock trials and latency to jump in Phase 2 when the response had been learned under normal conditions. Herz (1968) found a similar impairment with scopolamine on the pole-jump response. but this effect was dependent upon the time of drug administration: Scopolamine disrupted performance in rats that had learned the response but were not overtrained: scopolamine was ineffective in disrupting performance when the animals were overtrained and. in fact. the scopolamine group had shorter latencies. Herz suggested that there was an alteration of the susceptibility of the animal to scopolamine when the avoidance response became more completely established by training.

The possibility of state-dependent learning must also be considered, since Overton (1966) demonstrated that the pharmacologic effects produced by a number of drugs, including scopolamine, may act as a stimulus condition intrinsic to the performance of the response. Thus, a response impairment might occur if the animal were trained in the nondrug state and tested in the drug state, or vice versa. Daly (1968) argues against state-dependent learning as an explanation of scopolamine effects: In a hurdle-jump experiment with four groups (Saline-Saline, Saline-Scop. Scop-Scop, and Scop-Saline), he found that the performance of the shifted groups was no different from that of the nonshifted group. Also, Suits and Isaacson (1968) found that scopolamine had opposite effects on similar tasks, i.e., it facilitated performance on a two-way avoidance and disrupted performance on a one-way avoidance, which is also not consistent with a state-dependent explanation. Further, Carlton (1969) points out that the doses of scopolamine needed to get state-dependent learning were two to five times the amount used in most experiments.

Another possible explanation of the differences in the effects of scopolamine injections and septal lesions on jump-up performance is that scopolamine may have a more selective disruption of neural systems within the septohippocampal area. The hypothesis that septal lesions and anticholinergic compounds produce similar behavioral effects by interrupting a central cholinergic pathway does not mean that they disrupt the same neural systems. As Hamilton and Grossman (1969) point out, the neural systems affected by the two treatments may merely overlap and are probably not coterminous. The differences in behavior on some tasks may be due to the disruption of functions outside this area of overlap.

Additional studies involving more selective lesions and different drugs are necessary to determine more precisely the nature of behavioral inhibition. More systematic variations of the locus of small lesions or knife cuts involving only a single structure or pathway would allow for better description of these neural systems.

\section{REFERENCES}

Bolles. R. C. Avoidance and escape learning: Simultaneous acquisition of different responses. Journal of Comparative \& Physiological Psychology. 1969. 68. 355-358.

Bolles, R. C. Species specific defense reactions and aroidance learning. Psychological Review. 1970. 77. 32-48.

Bolles, R. C., \& Grossen. N. E. Effects of an informational stimulus on the acquisition of aroidance behavior in rats. Journal of Comparative \& Physiological Psychology. 1969. 68. 90-99.

Brown. C. C.. Reus. J. F.. \& Webb. G. A. A new constant current stimuiation circuit. International Conference of Medical Electronics. 1961. P. 200.

Carlton, P. L. Brain-acetylcholine and inhibition. In J. T. Tapp (Ed.), Reinforcement and behavior. New York: Academic Press, 1969.

Carlton. P. L. Some effects of scopolamine. atropine, and amphetamine in three behavioral situations. Pharmacologist. $1961,3,60$.

Daly, H. B. Disruptive effects of scopolamine on fear conditioning and on instrumental escape learning. Journal of Comparative \& Physiological Psychology. 1968, 66. 579-583.

D'Amato, M. R. Role of anticipatory responses in avoidance conditioning: An important control. Psychonomic Science. 1967, 8, 91 .

Deagle, J. H., \& Lubar. J. F. Effect of septal lesions in two strains of rats on one-way and shuttle avoidance acquisition. Journal of Comparative \& Phy siological Psy chology, 1971. 77. 277-281.

deGroot, J. The rat forebrain in stereotaxic coordinates. Amsterdam: Noorde-Hollanshe Uitgevers Maatschappij, 1959.

Donovick, P. J. Effects of localized septal lesions on hippocampal EEG activity and behavior in rats. Journal of Comparative \& Physiological Psychology, 1968, 66, 569-578.

Douglas. R. J., \& Isaacson, R. L. Spontaneous alternation and scopolamine. Psychonomic Science, 1966, 4. 383-384.

Federer. W. T. Experimental design. New York: Macmillan. 1955.

Fox, S. S., Kimble, D. P.. \& Lickey. M. E. Comparison of caudate nucleus and septal-area lesions on two types of avoidance behavior. Journal of Comparative \& Physiological Psychology. 1964. 58, 380-386.

Hamilton. L. W. Active avoidance impairment following septal lesions in cats. Journal of Comparative \& Physiological Psychology, 1969, 69, 420-431.

Hamilton, L. W. Behavioral effects of unilateral and bilateral septal lesions in rats. Physiology \& Behavior. 1970. 5. 855-859.

Hamilton, L. W. Intrabox and extrabox cues in avoidance responding: Effects on septal lesions. Journal of Comparative \& Physiological Psychology, 1972. 78. 268-273.

Hamilton, L. W.. \& Grossman. S. P. Behavioral changes following disruption of central cholinergic pathways. Journal of Comparative \& Physiological Psychology. 1969. 69. 76-82.

Hamilton, L. W., Kelsey. J. E.. \& Grossman. S. P. Variations in behavioral inhibition following different septal lesions in rats. Journal of Comparative \& Phýsiological Psychology. 1970. 70. 79-86.

Hamilton, L. W., McCleary. R. A.. \& Grossman. S. P. Behavioral effects of cholinergic septal blockade in the cat. Journal of Comparative \& Physiological Psychology. 1968, 66. $563-568$.

Hearst. E. Effects of scopolamine on discriminated responding in the rat. Journal of Pharmacology \& Experimental Therapeutics. 1959. 126. 349-358.

Herz. A. Some actions of cholinergic and anticholingergic drugs on reactive behavior. In P. B. Bradley and $\mathbf{M}$. Fink (Eds.). Progress in brain research. Vol. 28. New York: Elsevier. 1968.

King. F. A. Effects of septal and amygdaloid lesions on emotional behavior and conditioned aroidance responses in 
the rat. Journal of Nervous \& Mental Diseases, 1958, 126, 57-63.

Kriekhaus, E. E., Simmons, H. J., Thomas, G. J., \& Kenyon, J. Septal lesions enhance shock avoidance behavior in the rat. Experimental Neurology, 1964, 9, 107-113.

Lubar, J. F. Effect of medial cortical lesions on the avoidance behavior of the cat. Journal of Comparative \& Physiological Psychology, 1964, 58, 38-46.

McCleary, R. A. Response specificity in the behavioral effects of limbic system lesions in the cat. Journal of Comparative \& Physiological Psychology, 1961, 54, 605-612.

McCleary, R. A. Response-modulating functions of the limbic system: Initiation and suppression. In E. Stellar and J. M. Sprague (Eds.), Progress in physiological psychology. Vol. 1. New York: Academic Press, 1966.

McNew, J. J., \& Thompson, R. Role of the limbic system in active and passive avoidance conditioning in the rat. Journal of Comparative \& Physiological Psychology, 1966, 61, 173-180.

Meyers, B. Some effects of scopolamine on a passive avoidance response in rats. Psychopharmacologia, 1965, 8, 111-119.

Meyers, B., Roberts, K. H., Riciputi, R. H., \& Domino, E. F. Some effects of muscarinic cholingergic blocking drugs on behavior and electrocortigram. Psychopharmacologia, 1964, 5 , 289-300.

Miczek, K. A., Kelsey, J. E., \& Grossman, S. P. Time course of effects of septal lesions on avoidance response suppression, and reactivity to shock. Journal of Comparative \& Physiological Psychology, 1972, 79, 318-327.

Moore, R. Y. Effects of some rhinencephalic lesions on retention of conditioned avoidance behavior in cats. Journal of
Comparative \& Physiological Psychology, 1964, 57, 65-71.

Olton, D. S., \& Isaacson, R. L. The importance of spatial location in active avoidance tasks. Journal of Comparative \& Physiological Psychology, 1968, 65, 535-539.

Overton, D. A. State-dependent learning produced by depressant and atropine-like drugs. Psychopharmacologia, 1966, 10, 7-31.

Rich, I., \& Thompson, R. Role of the hippocampo-septal system, thalamus, and hypothalamus in avoidance conditioning. Journal of Comparative \& Physiological Psychology, 1965, 59, 66-72.

Siegel, S. Nonparametric statistics for the behavioral sciences. New York: McGraw-Hill, 1956.

Squire, L. R. Effects of pretrial and posttrial administration of cholinergic and anticholinergic drugs on spontaneous alternation. Journal of Comparative \& Physiological Psychology, 1969, 69, 69-75.

Suits. E.. \& Isaacson, R. L. The effects of scopolamine hydrobromide on one-way and two-way avoidance learning in rats. International Journal of Neuropharmacology, 1968, 7, 441-446.

Winer, B. J. Statistical principles in experimental design. New York: McGraw-Hill, 1962.

Zucker, I. Effects of lesions of septal-limbic area on the behavior of cats. Journal of Comparative \& Physiological Psychology, $1965,60,344-352$.

Zucker, I., \& McCleary, R. A. Perseveration in septal cats. Psychonomic Science, 1964, 1, 387-388.

(Received for publication November 30, 1972; revision received March $15,1973$. 